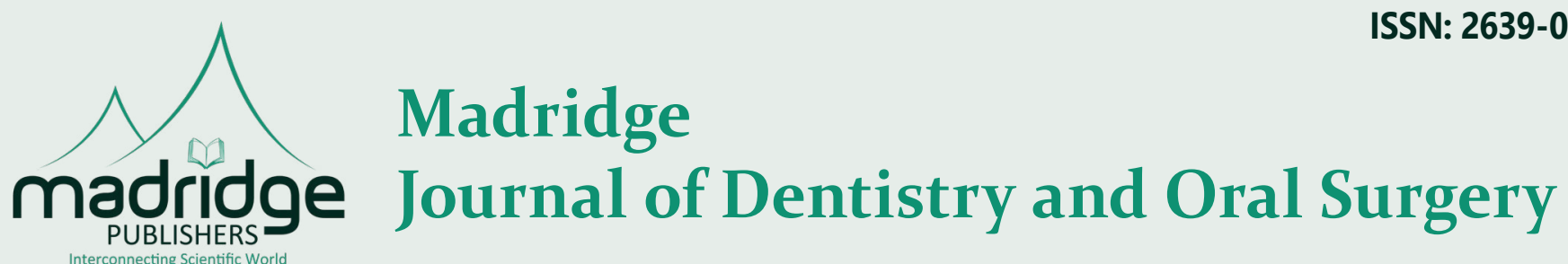

Interconnecting Scientific World

Research Article

Open Access

\title{
Reducing Oversized Tooth Dimensions by Using Porcelain laminate Veneers Designed by Diagnostic Additive Wax-Up and Indirect Resin Composite Mock Up
}

\author{
Hamit Serdar Çötert ${ }^{*}$ \\ Ege University, Faculty of Dentistry, Department of Prosthodontics, İzmir, Turkey
}

\section{Article Info}

\section{*Corresponding author: Hamit Serdar Çötert Ege University, Faculty of Dentistry \\ Dept. of Prosthodontics \\ 35100, Bornova, Izmir, Turkey \\ Tel: +902323880327 \\ Fax: +902323880325 \\ E-mail: cotert@gmail.com}

\section{Received: August 12, 2016 \\ Accepted: August 25, 2016 \\ Published: August 30, 2016}

\section{Citation: Cotert HS. Reducing Oversized Tooth Dimensions by Using Porcelain Laminate Veneers Designed by Diagnostic Additive Wax-Up and Indirect Resin Composite Mock Up. Madridge J Dent Oral Surg. 2016; 1(1): 13-18. \\ doi: $10.18689 / \mathrm{mjdl}-1000103$}

Copyright: @ $₫ 2016$ The Author(s). This work is licensed under a Creative Commons Attribution 4.0 International License, which permits unrestricted use, distribution, and reproduction in any medium, provided the original work is properly cited.

Published by Madridge Publishers

\begin{abstract}
Objectives: Unfavorable appearance of the oversized anterior teeth and the collateral disturbances such as positional and/or proportional irregularities and also crowding may create major challenges in front of dental practitioners.
\end{abstract}

Clinical Considerations: Diagnostic additive wax-up, vacuum-formed clear template, resin composite mock-up and silicone index preparation guide, employed for the esthetic improvement of a patient presenting over contoured and crowded anterior dentition, are presented.

Conclusions: Preoperative designing approaches such as additive wax-up and resin composite mock-up made by the clear template and the use of the silicone index as a preparation guide; were found successful for minimizing the tooth form and correction of the dental arch disturbances by using porcelain laminate veneers.

Clinical Significance: Unsightly over contoured and crowded teeth may reduce by using porcelain laminate veneers and the preoperative planning methods guarantee the final success and the patient satisfaction.

Keywords: Porcelain Laminate Veneer; PLV; Indirect Mock-Up; Diagnostic Wax-Up; Oversized Teeth.

\section{Introduction}

Porcelain laminate veneers (PLVs) have become the most popular restorations in order to improve the esthetic appearance of anterior dentition. They have been known as conservative, durable and esthetic anterior restorations for a long time [1-6].

Simplified tooth preparation techniques employing the use of depth cutters guided by the existing tooth surface, were described by several reports [1,7-14].

Additive diagnostic procedures such as the wax-up or mock-up to compensate the loss of the tooth substance and novel tooth preparation techniques driven by the final volume of the restoration were described recently by Magne and Belser [15]. These techniques were found useful to preserve more enamel tissue and, as a consequence, more predictable bonding, biomechanics, and esthetics [15-21].

PLVs have been preferred in order to correction of the unsightly anterior esthetic appearance of discoloured and/or structurally disintegrated teeth due to the acquired lesions such as the fracture, wear and decay and also congenitally malformed teeth, as 
well as esthetic reshaping of anterior teeth and management of diastemas instead of full-coverage restorations [22-42].

Improving the unfavorable esthetic appearance of oversized and crowded anterior dentition, reconstruction of the severe deep bite and uncomfortably sharp and perpendicular anterior guidance by reducing the oversized tooth dimensions with PLVs designed by diagnostic additive wax-up and indirect resin composite mock-up, were described in this clinical report.

\section{Clinical Report}

A 28 years-old female attended with the anterior esthetic complaints. Teeth were observed as oversized and crowded and the patient was unhappy from her unpleasant dental appearance (Figure 1). In addition to the esthetic complaints, patient has also complained from the uncomfortable chewing function. Intraoral examination revealed that the protrusive movement of the mandible was strictly blocked due to the deep overbite and the perpendicular incisive pathway. General health status was good, intraoral and radiological examinations revealed that teeth were sound and free from the carious lesions and the muco-gingival status was fair.

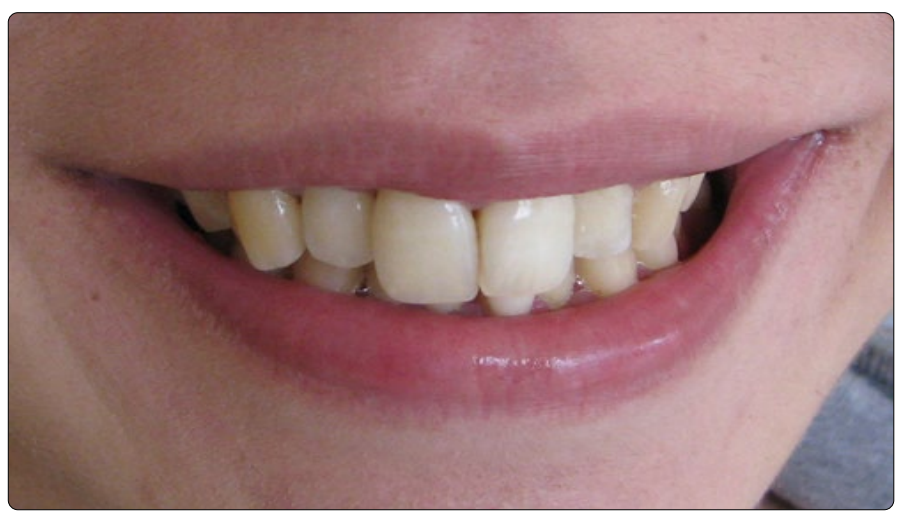

Figure 1: Oversized and crowded anterior dentition.The deep overbite and the perpendicular incisive pathway were strictly blocking the protrusive movement of the mandible.

Recontouring of the anterior teeth by reducing incisogingival diameters and correcting of the dental arch irregularities by employing PLVs were planned to establish proper anterior esthetics.

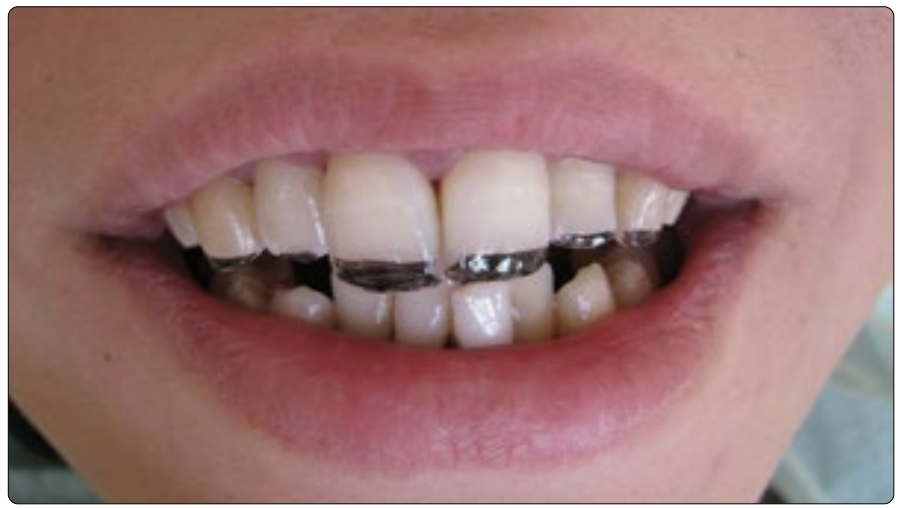

Figure 2: Proposal of desired reductions.

Desired inciso-gingival diameters of the upper and lower anterior teeth and the required reductions were marked clinically by using permanent pen and the proposed final dimensions were also evaluated and approved by the patient (Figure 2). Volumes and the borders of the pulp chambers were checked radiographically. Preliminary impressions have been made with stock trays and irreversible hydrocolloide impression material (CA-37, Cavex Dental BV, Haarlem, Holland) were poured in dental stone (Gilodur, Giulini Chemie; Ludwigshafen, Germany) and the diagnostic casts were obtained (Figure 3).

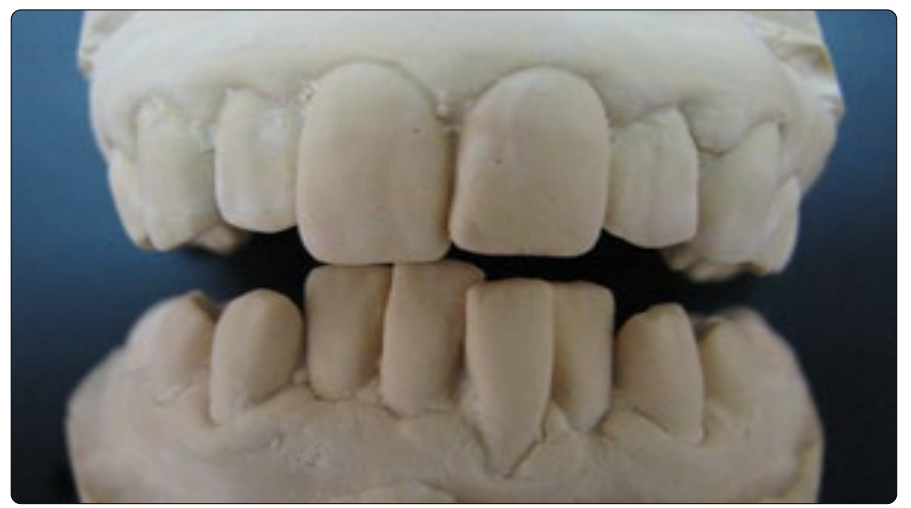

Figure 3: Diagnostic casts.

Proposed reductions were made on the diagnostic casts (Figure 4), wax-up was made with sculpturing wax (Avantgarde Opaque Gray, Renfert GmbH, Hilzingen, Germany) where necessary (Figure 5) and the altered casts were duplicated in dental stone (Gilodur, Giulini Chemie) by using irreversible hydrocolloide impression material (CA-37, Cavex Dental BV). Clear resin templates were vacuum-formed and trimmed (Figure 6).

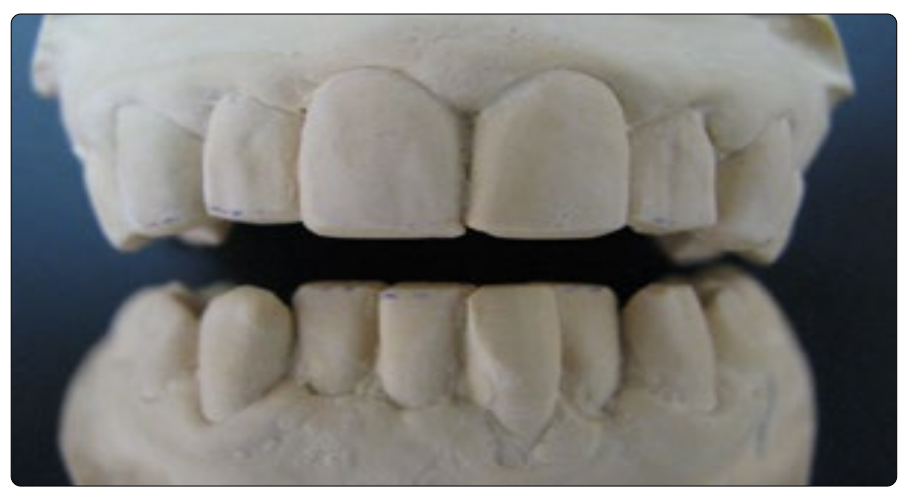

Figure 4: Altered diagnostic casts in order to reduction proposal.

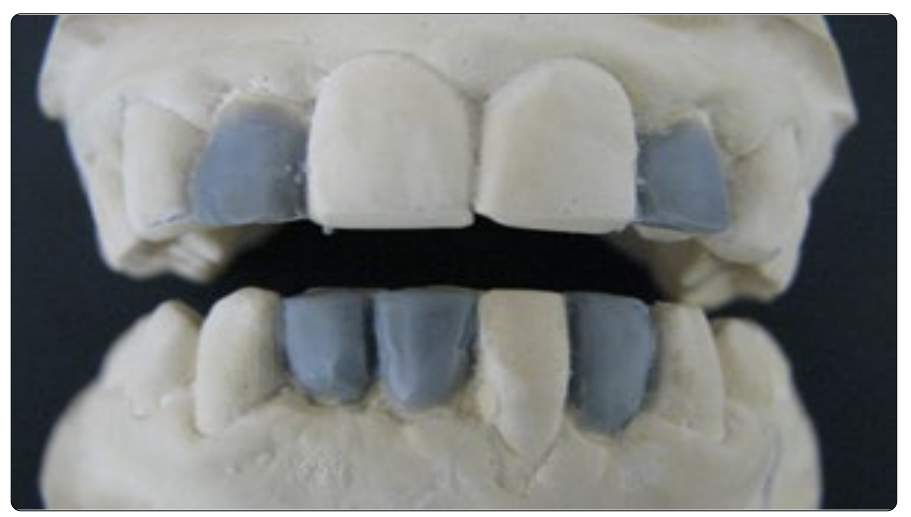

Figure 5: Additional wax-ups on altered diagnostic casts. 


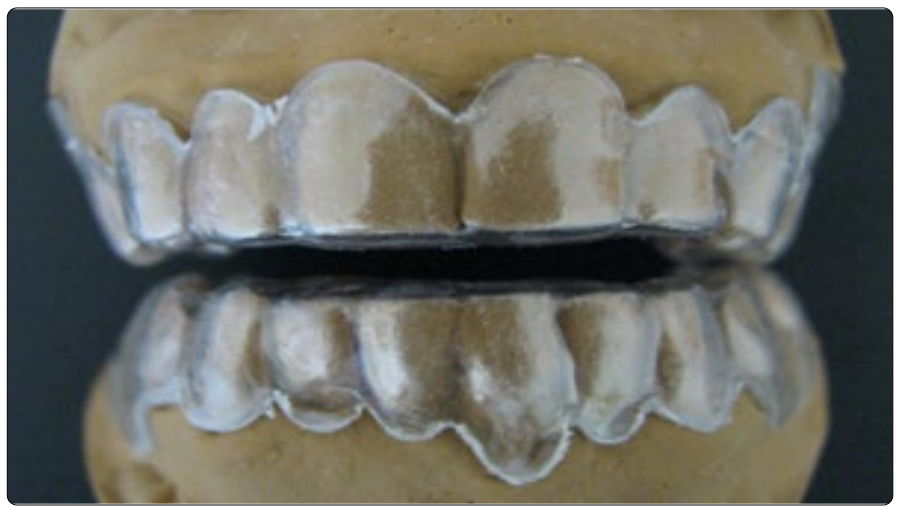

Figure 6: Clear resin templates vacuum-formed on the casts duplicated from the altered and waxed diagnostic casts.

Over-contours were eliminated under the guidance of the templates and the passive fit was obtained, required teeth were spot-etched at the mid-point of the facial surface with $37 \%$ ortho phosphoric acid (Totaletch, Ivoclar-Vivadent, Schaan, Liechtenstein) for $10 \mathrm{~s}$, rinsed, and dried; templates were filled with flowable resin (Tetric Flow, Ivoclar-Vivadent) and placed. Material was light polymerized with an energy density of $480 \mathrm{mw} / \mathrm{cm} 2$ (Polofil Lux, Voco, Cuxhaven, Germany) for at least 40 s from labially and palatinally after the excess material has been swept-off from the borders. Templates were peeled-out, upper and lower indirect composite mock-ups were uncovered (Figure 7).

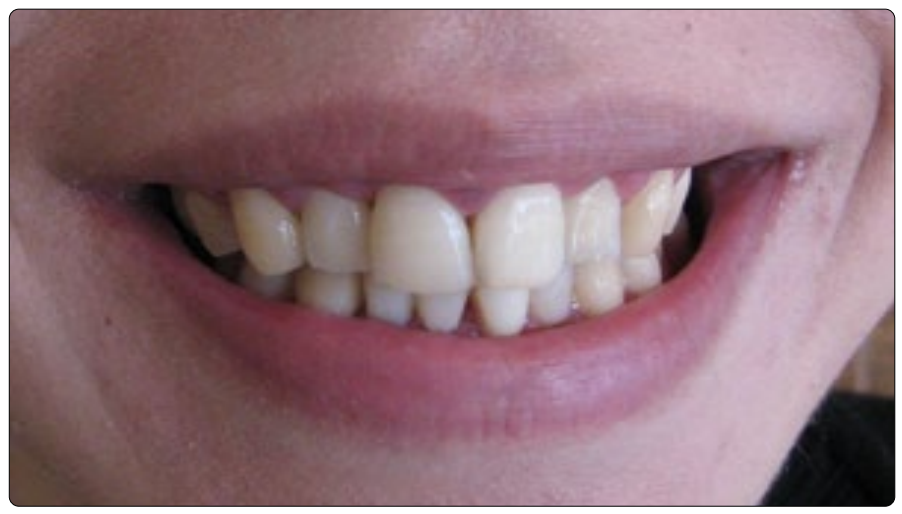

Figure 7: Indirect resin composite mock-ups formed in the templates.

Patient was permitted to use and observe the esthetic outcomes of the composite mock-ups for a week and the final improvements were made with minor addings and trimmings of the composite material where necessary. After the establishment of the balanced esthetics, acceptance of the final smile design and establishment of the proper anterior guidance a silicone index was made from the putty elastomeric impression material (Stabisil Putty, Cavex Dental BV). Incisal region of the silicone index was cut-off. Teeth were prepared as to maintain sufficient space between the prepared surface and the index intaglio (Figure 8). Supragingival chamfered cervical finishing lines; proximal feathers, incisal overlaps and smooth margins were created. The aim of the reducing oversized contours compelled the preparation technique to be deeper than conventional. For this reason, enamel tissue compulsorily eliminated and the dentine tissue was exposed. An extraordinary attention was paid to protect the biologic integrity of the pulp-dentine complex and keep its vitality during the entire preparation process. Dimensions and the contours of the pulp chamber were traced on the periapical radiograms, real measurements were calculated by using image measurements and the preparations were performed under the guidance of these measurements. A reliable thickness of sound dentine tissue was left on the pulpal tissue and an effective water-cooling was established on the prepared surface and bur. To obtain optimal gingival displacement, a retraction cord \#00 (Ultrapack, Ultradent; Salt Lake City, UT, USA) soaked with hemo static solution (ViscoStat, Ultradent) was used.

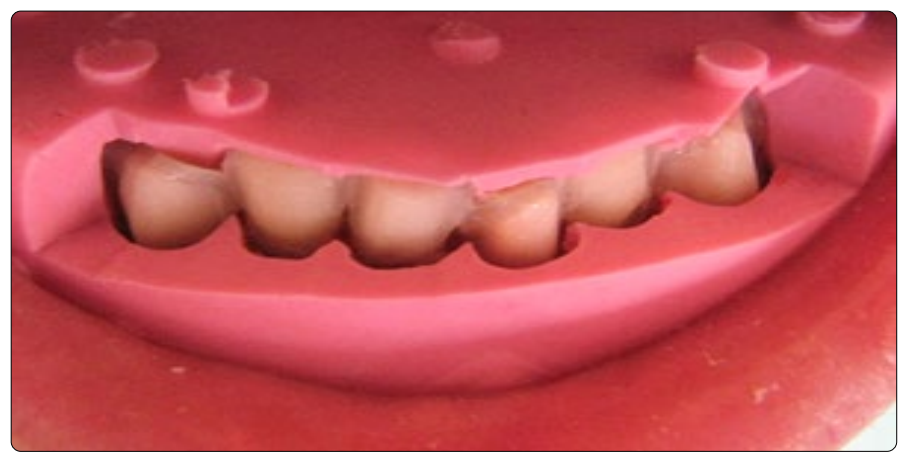

Figure 8: Elastomeric index guided preparation of the teeth.

Vacuum-formed transparent template was also used for the temporization. It was filled with composite resin based temporary crown-bridge material (Protemp 4, 3M-ESPE). Subsequently, the provisional restorations were cemented with eugenol-free temporary cement (Temp-Bond NE, Cavex Dental).

Impressions were made with a vinyl polysiloxane elastomeric material (Pentasoft Duo-Mix, 3M ESPE), mixed by an automatic mixer (Pentamix, 3M ESPE) and put on individual trays. Master casts were poured with a Type IV dental stone (Glastone Dental Stone, Dentsply; Milford, DE, USA). An irreversible hydrocolloid material and the stock tray were used for the impression of the opposing dentition and inter occlusal registration was also made.

PLVs were made of a heat-pressed ceramic material (IPS e-max Press, Ivoclar-Vivadent). Intaglios were sandblasted with 50- $\mu \mathrm{m} \mathrm{Al}_{2} \mathrm{O}_{3}$ particles (Korox, Bego, Bremen, Germany), etched for $40 \mathrm{~s}$ with $9.5 \%$ hydrofluoric acid (Porcelain Etch, Ultradent), rinsed and cleaned ultrasonically first in detergent solution and then in distilled water by using an ultrasonic cleaner (Sonorex; Bandelin, Germany), dried, and silanized (Silane, Ultradent).

Provisional restorations and temporary cement remnants were eliminated from prepared tooth surfaces. Teeth were cleaned with non aromatic pumice and rinsed. Moisture control was established. Prepared dentine surfaces were conditioned with $37 \%$ ortho phosphoric acid (Ultra etch, Ultra dent) for $10 \mathrm{~s}$, rinsed, and dried. Marginal enamel tissue was etched with $37 \%$ orthophosphoric acid (Ultraetch, Ultradent) for $30 \mathrm{~s}$, rinsed, and dried. A dentine-bonding agent (Excite, Ivoclar-Vivadent; Schaan, Liechtenstein) was used before cementation where the dentine was exposed. The restorations were cemented with a dual-curing resin-cement (Variolink II, Ivoclar-Vivadent). Color matching of the prepared teeth was 
performed according to the manufacturer's instructions. Excess cement was removed after $10 \mathrm{~s}$ of preliminary light polymerization, and the restorations were then completely light polymerized with an energy density of $480 \mathrm{~mW} / \mathrm{cm} 2$ (Polofil Lux, Voco) for at least 120s from all aspects of the tooth (Figure 9). The patient was instructed about the use of her laminate veneers and was recalled 1 week later to assess the oral hygiene and gingival response. Esthetic satisfaction was well addressed. Smoother and functional anterior guidance was constructed. After the first year of use, restorations are in-situ, sound, functional and free from any complication (Figure 10).

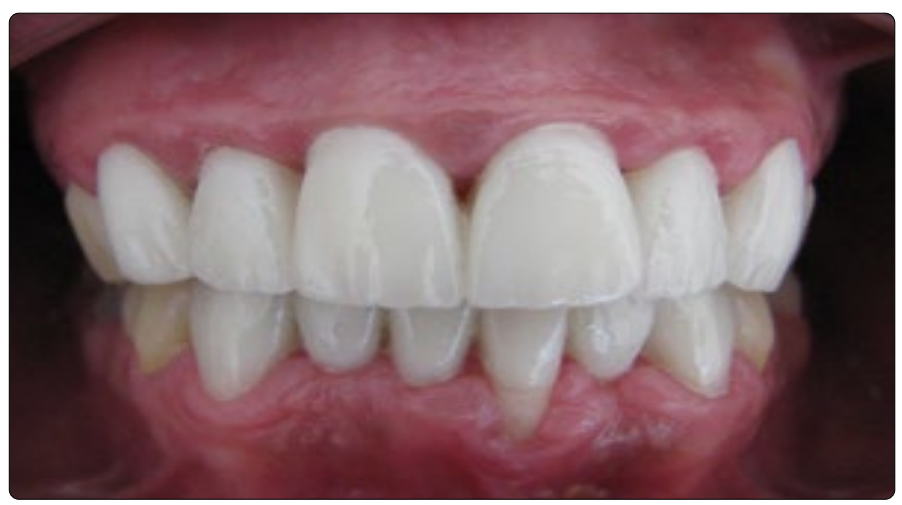

Figure 9: PLV restorations in-situ. Inciso-gingival and mesio-distal diameters were reduced, crowding was corrected, bite was diminished, incisive pathway was smoothened and the protrusive movement was set free.

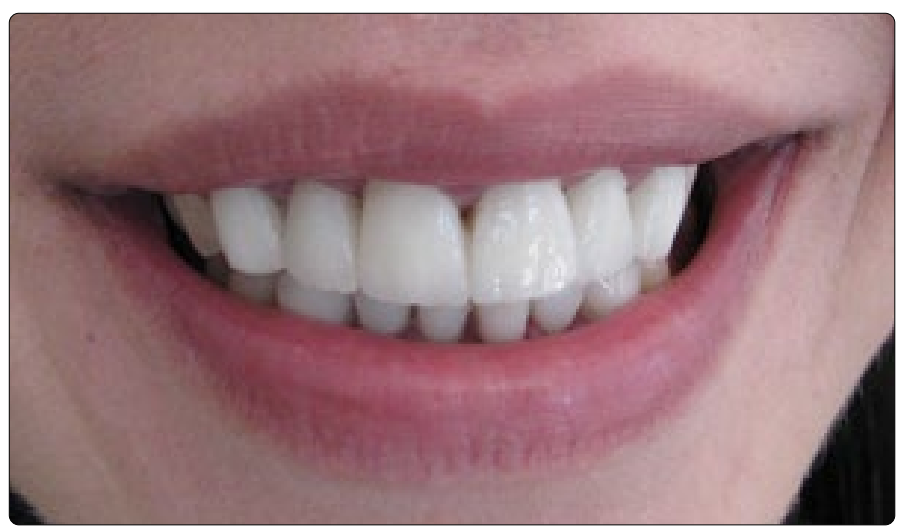

Figure 10: After the first year of use, restorations are functional and free from any complication.

\section{Discussion}

PLVs have been used for more than three decades for esthetic improvement of anterior dentition with minimally invasive preparation. Modern ceramic materials upgraded the esthetic performance while the luting materials and techniques providing both predictable and long lasting service duration [39-41].

Varying types of dental problems in anterior region solved by PLVs, were described in several reports.

PLVs provide satisfactory esthetic outcomes and preserve sound structures of the dis coloured teeth [22-26]. Colour stability, mechanical strength, clinical longevity, esthetic appearance and periodontal compatibility of dental ceramics, make this materials good choices for such treatment [22].
Compromised sight of malformed teeth such as conoid or peg laterals and/or microdontia, can successfully be improved by PLV restorations [27-30]. An accurate diagnostic and interdisciplinary approach was advised for obtaining esthetic, conservative, predictable and long lasting results in anterior maxillary dentition [27].

Management of anterior diastemata can be accomplished in several ways and the PLV is one of the most favorites [3132]. The extensions of PLV in diastema closure have more of an esthetic than functional consideration according to Chander and Phadmanaban [31]. Angulations and the loading level acting on free extensions were found important [31] Dimensions of the diastema closing PLVs, have been advised to be calculated from the tables of mean measurements [32].

According to the reviewed literature [33-34], treatment of amelogenesis imperfect a cases exhibiting discoloured and mutilated teeth can be performed with PLVs and the patient's esthetic and functional expectations can successfully be attained.

Tooth transformations should also be included to the above-mentioned indications. One type of tooth can be transformed into another by using correct restorative procedures. Griffin [28] advised that, a meticulous attention must be paid to perform the most suitable preparation and gingival contours, to create the illusion that the teeth are in their correct position.

PLVs were found useful for young adult patients requiring esthetic restorations [37] and/or advanced corrections following orthodontic treatment [38].

Incisal lengthening and recontouring of worn dentition [35] and restoration of fractured teeth with PLVs [36] were also met in reviewed literature. However, studies reporting the methodology of reducing tooth dimensions by employing PLVs, are not frequent.

Anterior esthetic appearance was improved with PLVs in present case. Final restorations were made shorter than original in order to obtain proper proportions between the inciso-gingival height and mesio-distal width of the teeth Also, dental crowding was managed with preoperative waxup and indirect mock-up applications.

Magne and Magne [16] reported that diagnostic wax-up of preliminary castis the initial step to obtain restorative goal. This procedure requires proficiency in tooth anatomy, but also a good perception of the patient's personality and expectations from dental treatment. Additionally, the diagnostic wax-up procedure is able to guide the crownlengthening surgery by indicating the most suitable proportions. Gingival and bony margins may be recontoured and repositioned surgically by using crown-lengthening procedure [42]. A well diagnosed, planned and obtained increase in the clinical crown height, can improve the retention and resistance of the restoration, as well as aesthetics. Waxingup of the preliminary casts as a part of diagnostics and treatment planning can provide valuable information to the dentist, laboratory, and patient, as well as acting as a useful 
guide for gingival and osseous recontouring in order to achieve a pleasing aesthetics [42].

Various Mock-up applications were described and advised in reviewed literature [15-21]. Direct intra-oral application of auto polymerizing methacrylate [15-18] and composite resins [19-21] were advised generally. In present study, waxed diagnostic cast was duplicated with dental stone and a clear template was vacuum-formed on this duplicated stone cast. Mock-up was made with flow able resin composite by using the template. This indirect approach facilitated the clinical application, improved the mock-up quality and shortened the time spent clinically.

Following final corrections, silicone index was made as described in previous reports [7][8][15][19-21][41]. Final preparations were performed with the guidance of the silicone index according to the final contours of the restoration. Magne and colleagues [15-19] reported that, clinicians should be able to perform tooth preparations that are both more accurate and also higher in quality in an extremely timeefficient fashion compared with traditional methods by using a silicone index. In present study, requirement of the reducing oversized contours enforced the clinician to ground heavier than routine. This kind of a preparation may provoke such as post-operative sensitivity or worse, dental pulp may be affected irreversibly. In order to avoid such complications, morphology and the neighborhood of the pulpal chamber with the prepared surfaces should be considered during the each phase of the preparation and preoperative planning as described in precious section.

Techniques employed in this study; preoperative additive wax-up, composite mock-up by using a clear template and silicone key as a preparation guide, were found useful for reducing tooth dimensions by employing PLVs. However, described techniques may successfully be used in recontouring of the various unsightly teeth.

\section{Conclusions}

\section{Following conclusions were withdrawn:}

Diameters of clinical crown may be reduced in order to gain more esthetic appearance.

Diagnostic wax-up enhances the predictability of treatment by modeling the desired result in wax prior to treatment.

Duplication of the waxed diagnostic cast with dental stone is easy, quick, inexpensive and necessary for the vacuum-forming procedure.

Vacuum-formed clear template facilitates the production of the mock-up and saves the time.

Resin composite mock-up provides patient feedback and may be improved intra orally.

Mock-up driven preoperative planning and preparation provides satisfactory esthetic outcomes and preserves sound tooth structure in PLV applications.
Conflicts of Interest: The authors declare no conflicts of interest with this submission.

\section{References}

1. Cotert HS, Dundar M, Ozturk B. The Effect of Various Preparation Designs on the Survival of Porcelain Laminate Veneers. J Adhes Dent. 2009; 11(5): 405-411.

2. Beier US, Kapferer I, Burtscher D, Dumfahrt H. Clinical performance of porcelain laminate veneers for up to 20 years. Int J Prosthodont. 2012; 25(1):79-85.

3. Aykor A, Ozel E. Five-year clinical evaluation of 300 teeth restored with porcelain laminate veneers using total-etch and a modified self-etch adhesive system. Oper Dent. 2009; 34(5): 516-23. doi: 10.2341/08-038C

4. Burke FJ, Lucarotti PS. Ten-year outcome of porcelain laminate veneers placed within the general dental services in England and Wales. J Prosthodont. 2009; 18(7):577-81.

5. Wiedhahn $\mathrm{K}$, Kerschbaum T, Fasbinder DF. Clinical long-term results with 617 Cerec veneers: a nine-year report. Int J Comput Dent. 2005; 8(3):23346.

6. Dumfahrt $\mathrm{H}$, Schaffer $\mathrm{H}$. Porcelain laminate veneers. A retrospective evaluation after 1 to 10 years of service: Part II--Clinical results. Int J Prosthodont. 2000; 13(1): 9-18.

7. Dumfahrt H. Porcelain laminate veneers. A retrospective evaluation after 1 to 10 years of service: Part I--Clinical procedure. Int J Prosthodont 1999; 12(6): 505-513.

8. Brunton PA, Aminian A, Wilson NH. Tooth preparation techniques for porcelain laminate veneers.BrDentJ. 2000;189(5):260-2. doi: 10.1038/ sj.bdj.4800739

9. Brunton PA, Wilson NH. Preparations for porcelain laminate veneers in general dental practice. Br Dent J. 1998; 184(11): 553-6.

10. Calamia JR. Etched porcelain facial veneers: A new treatment modality based on scientific and clinical evidence. NYJ Dent. 1983; 53(6): 255-259.

11. Magne P, Douglas WH. Design optimization and evolution of bonded ceramics for the anterior dentition: A finite element analysis. Quintessence Int. 1999; 30(10): 661-672.

12. da Costa DC, Coutinho M, de Sousa AS, Ennes JP. A meta-analysis of the most indicated preparation design for porcelain laminate veneers. $J$ Adhes Dent. 2013; 15(3): 215-20. doi: 10.3290/j.jad.a29587

13. Atsu SS, Aka PS, Kucukesmen HC, Kilicarslan MA, Atakan C. Age-related changes in tooth enamel as measured by electron microscopy: implications for porcelain laminate veneers. J Prosthet Dent. 2005; 94(4): 336-41. doi: 10.1016/j.prosdent.2005.08.008

14. Ferrari $M$, Patroni $S$, Balleri P. Measurement of enamel thickness in relation to reduction for etched laminate veneers. Int J Periodontics Restorative Dent. 1992; 12(5): 407-413.

15. Magne $P$, Belser UC. Novel porcelain laminate preparation approach driven by a diagnostic mock-up. J Esthet Restor Dent. 2004; 16(1): 7-16.

16. Magne $P$, Magne $M$. Use of additive wax up and direct intraoral mockup for enamel preservation with porcelain laminate veneers. Eur J Esthet Dent. 2006; 1(1): 10-9.

17. Gurel G. Porcelain laminate veneers: minimal tooth preparation by design. Dent Clin North Am. 2007; 51(2): 419-31. doi: 10.1016/j. cden.2007.03.007

18. Simon $H$, Magne P. Clinically based diagnostic wax-up for optimal esthetics: the diagnostic mock-up. J Calif Dent Assoc. 2008; 36(5): 35562.

19. Reshad M, Cascione D, Magne P. Diagnostic mock-ups as an objective tool for predictableoutcomes with porcelain laminate veneers inesthetically demanding patients: a clinical report. J Prosthet Dent. 2008; 99(5): 333-9. doi: 10.1016/S0022-3913(08)00056-5 
20. Behle C. Placement of direct composite veneers utilizing a silicone buildup guide and intraoral mock-up. Pract Periodontics Aesthet Dent. 2000; 12(3): 259-66.

21. Kovacs BO, Mehta SB, Banerji S, Millar BJ. Aesthetic smile evaluation--a non-invasive solution. Dent Update. 2011; 38(7): 452-4.

22. Freire $A$, Archegas LR. Porcelain laminate veneer on a highly discoloured tooth: a case report. J Can Dent Assoc. 2010; 76: 126.

23. Ratnaweera PM, Fukagawa N, Tsubota Y, Fukushima S. Microtensile bond strength of porcelain laminate veneers bonded to fluorosed teeth. J Prosthodont. 2009; 18(3): 205-10. doi: 10.1111/j.1532-849X.2008.00403.x

24. Jun SK, Wilson S. Restoration of severely discolored maxillary anterior teeth with porcelain laminate veneers. Pract Proced Aesthet Dent. 2008 Jun; 20(5): 285-7.

25. Sadan A, Lemon RR. Combining treatment modalities for tetracyclinediscolored teeth. Int J Periodontics Restorative Dent. 1998; 18(6): 564-71.

26. Nixon RL. Masking severely tetracycline-stained teeth with ceramic laminate veneers. Pract Periodontics Aesthet Dent. 1996; 8(3): 227-35; quiz 237.

27. Pena CE, Viotti RG, Dias WR, Santucci E, Rodrigues JA, Reis AF. Esthetic rehabilitation of anterior conoid teeth: comprehensive approach for improved and predictable results. Eur J Esthet Dent. 2009; 4(3): 210-24.

28. Griffin JD Jr. Correction of congenitally missing lateral incisors with porcelain veneers. Pract Proced Aesthet Dent. 2006; 18(8): 475-80.

29. Braun J. Treatment of the peg lateral incisor: a case study. J Indiana Dent Assoc. 2001; 80(1): 16-7.

30. Aherne T. Use of porcelain laminate veneers for the correction of isolated microdontia. Pract Periodontics Aesthet Dent. 1999; 11(1): 84-6, 88.

31. Chander NG, Padmanabhan TV. Finite element stress analysis of diastema closure with ceramic laminate veneers. J Dent. 2009; 18(7): 577-81. doi: 10.1111/j.1532-849X.2009.00490.x
32. Marais JT. A successful combination of conflicting approaches to diastema closure--a case report. SADJ. 1998; 53(5): 231-4.

33. Sadighpour L, Geramipanah F, Nikzad S. Fixed rehabilitation of an ACP PDI class III patient with amelogenesis imperfecta. J Prosthodont. 2009; 18(1): 64-70. doi: 10.1111/j.1532-849X.2008.00368.x

34. Ozturk N, Sari Z, Ozturk B. An interdisciplinary approach for restoring function and esthetics in a patient with amelogenesis imperfecta and malocclusion: a clinical report. J Prosthet Dent. 2004; 92(2): 112-5. doi: $10.1016 /$ S0022391304002288

35. Gresnigt $\mathrm{M}$, Ozcan $\mathrm{M}$, Kalk W. Esthetic rehabilitation of worn anterior teeth with thin porcelain laminate veneers. Eur J Esthet Dent. 2011; 6(3): 298-313.

36. Turkaslan S, Turna C. The esthetic rehabilitation of misplaced dental arch after fracture of anterior maxillae: a case report. Cases J. 2009; 2: 8723. doi: 10.4076/1757-1626-2-8723

37. Chen YW, Raigrodski AJ. A conservative approach for treating young adult patients with porcelain laminate veneers. J Esthet Restor Dent 2008; 20(4): 223-36. doi: 10.1111/j.1708-8240.2008.00184.x

38. Lampreia M, Perez J. Aesthetic porcelain laminate veneer restoration following orthodontic treatment: sequential technique. Pract Proced Aesthet Dent. 2008; 20(9): 545-7.

39. Lerner JM. Conservative aesthetic enhancement of the maxillary anterior using porcelain laminate veneers. Pract Proced Aesthet Dent. 2006; 18(6) $361-6$

40. Bloom DR, Padayachy JN. Aesthetic changes with four anterior units. $\mathrm{Br}$ Dent J. 2006; 11; 200(3): 135-8. doi: 10.1038/sj.bdj.4813192

41. Cutbirth ST, Geller W. Restoration of maxillary anterior teeth with porcelain laminate veneers. Pract Periodontics Aesthet Dent. 1999; 11(4): 443-5.

42. Malik K, Tabiat-Pour S. The use of a diagnostic wax set-up in aesthetic cases involving crown lengthening--a case report. Dent Update. 2010; 37(5): 303-4, 306-7. 